\title{
Coagulase-negative staphylococci species affect biofilm formation of other coagulase-negative and coagulase-positive staphylococci
}

\author{
Coralie Goetz, ${ }^{*}+$ Yannick D. N. Tremblay, ${ }^{*} \dagger$ Daphnée Lamarche, ${ }^{*}$ Andréanne Blondeau, ${ }^{*}$ Annie M. Gaudreau, ${ }^{*}$ \\ Josée Labrie, ${ }^{*}$ François Malouin, $† \ddagger$ and Mario Jacques* ${ }^{1}$ \\ *Department of Pathology and Microbiology, Faculty of Veterinary Medicine, Université de Montréal, St-Hyacinthe, Québec, Canada J2S 2M2 \\ †Canadian Bovine Mastitis and Milk Quality Research Network, St-Hyacinthe, Québec, Canada J2S 2M2 \\ ‡Department of Biology, Faculty of Science, Université de Sherbrooke, Sherbrooke, Québec, Canada J1K 2R1
}

\begin{abstract}
Coagulase-negative staphylococci (CNS) are considered to be commensal bacteria in humans and animals, but are now also recognized as etiological agents in several infections, including bovine mastitis. Biofilm formation appears to be an important factor in CNS pathogenicity. Furthermore, some researchers have proposed that CNS colonization of the intramammary environment has a protective effect against other pathogens. The mechanisms behind the protective effect of CNS have yet to be characterized. The aim of this study was to evaluate the effect of CNS isolates with a weak-biofilm phenotype on the biofilm formation of other staphylococcal isolates. We selected $10 \mathrm{CNS}$ with a weak-biofilm phenotype and 30 staphylococcal isolates with a strong-biofilm phenotype for this study. We measured biofilm production by individual isolates using a standard polystyrene microtiter plate assay and compared the findings with biofilm produced in mixed cultures. We confirmed the results using confocal microscopy and a microfluidic system with low shear force. Four of the CNS isolates with a weak-biofilm phenotype (Staphylococcus chromogenes $\mathrm{C}$ and E and Staphylococcus simulans $\mathrm{F}$ and $\mathrm{H}$ ) significantly reduced biofilm formation in approximately $80 \%$ of the staphylococcal species tested, including coagulase-positive Staphylococcus aureus. The 4 Staph. chromogenes and Staph. simulans isolates were also able to disperse pre-established biofilms, but to a lesser extent. We also performed a deferred antagonism assay and recorded the number of colony-forming units in the mixed-biofilm assays on differential or selective agar plates. Overall, CNS with a weak-biofilm phenotype did not inhibit the growth of isolates with a strong-biofilm phenotype. These results suggest that some CNS isolates can negatively affect the ability of other staphylococcal isolates and species
\end{abstract}

Received January 23, 2017.

Accepted April 26, 2017.

${ }^{1}$ Corresponding author: mario.jacques@umontreal.ca to form biofilms via a mechanism that does not involve growth inhibition.

Key words: mastitis, coagulase-negative staphylococci, biofilm, inhibition, dispersion

\section{INTRODUCTION}

Intramammary infections trigger an inflammatory response in the udder, which may lead to mastitis in cows. Mastitis is the most common and detrimental disease in the dairy industry, and it has a major economic impact on the production and quality of milk. Coagulase-negative staphylococci are the bacteria most frequently isolated from the intramammary environment in Canada (Fry et al., 2014) and other countries (Tenhagen et al., 2006; Pyörälä and Taponen, 2009; Sampimon et al., 2009). The CNS have traditionally been considered minor pathogens causing IMI, but are increasingly being recognized as emerging mastitis pathogens (Pyörälä and Taponen, 2009).

Conflicting results about the effect of CNS on the risk of a quarter acquiring a new IMI with a major pathogen have been reported in the literature. For example, CNS IMI or teat apex colonization have long been considered to have a protective effect (Rainard and Poutrel, 1988; Matthews et al., 1991). However, a meta-analysis revealed that observational studies did not report a protective effect of pre-existing IMI with CNS (Reyher et al., 2012a). Furthermore, the presence of CNS increased the probability of a new Staphylococcus aureus IMI (Reyher et al., 2012b) and new IMI in the ipsilateral quarter (Reyher et al., 2013). Overall, it has been proposed that any protective or negative effect of CNS on new IMI is probably species-dependent (Reyher et al., 2012a; Vanderhaeghen et al., 2014). The mechanisms behind the positive or negative effects of CNS have yet to be characterized.

Some CNS isolated from dairy cows can produce bacteriocins with antibacterial activity against other mastitis pathogens, including other CNS species, Staph. aureus, Streptococcus uberis, and Streptococcus agalactiae (dos Santos Nascimento et al., 2005; Ceotto et al., 
2010; Brito et al., 2011; Braem et al., 2014). These bacteriocins likely play an important role in interspecies competition in ecological niches such as the udder (De Vuyst and Leroy, 2007).

In addition to bacteriocins, biofilms formed by commensal bacteria at the surface of epithelial cells may prevent colonization by certain pathogens (Rickard et al., 2003; Kuboniwa et al., 2006). Biofilms are a universal trait of microorganisms; they are structured communities of bacterial cells enclosed in a self-produced matrix attached to surfaces (Costerton et al., 1999; Jacques et al., 2010). The thickness and the composition of the biofilm have an important role in its functionality. Specifically, the polymer matrix acts as a barrier and reduces or blocks the diffusion of antibiotics; a thicker biofilm may make it more difficult for antibiotics to penetrate the barrier and reach bacterial cells. Furthermore, electrostatic charges at the surface of the polymeric matrix will bind charged microbial agents and prevent them from reaching their effective concentration. As well, the protective barrier of the biofilms might not be limited to antimicrobials. For example, the ability to form biofilms might protect bacteria against host inflammatory cells in the mammary gland. Nutrient and oxygen gradients also develop during growth in biofilm, resulting in the presence of slow-growing or metabolically inactive bacterial cells that are less affected by antibiotics (Hathroubi et al., 2017). Although in vitro studies have focused mainly on single-species biofilms, multispecies biofilms are predominant in the context of host colonization and environmental conditions. Furthermore, chronic and biofilm-related infections may be facilitated by the persistence of polymicrobial biofilms (Burmølle et al., 2014; Miquel et al., 2016). Consequently, researchers are now focusing their efforts on understanding the complexity and interactions of

Table 1. Bacterial isolates with a negative-, weak-, or moderatebiofilm phenotype used in this study

\begin{tabular}{lll}
\hline Bacterial species and isolate & $\begin{array}{l}\text { Biofilm } \\
\text { phenotype }^{1}\end{array}$ & $\begin{array}{c}\text { Biofilm } \\
\left(\mathrm{A}_{490}\right)\end{array}$ \\
\hline Staphylococcus chromogenes & Weak & $0.300^{2}$ \\
A & Negative & $0.083^{2}$ \\
B & Negative & $0.074^{2}$ \\
C & Weak & $0.152^{2}$ \\
D & Negative & $0.089^{2}$ \\
E & Weak & $0.139^{2}$ \\
Staphylococcus simulans & Moderate & $0.652^{2}$ \\
F & Weak & $0.156^{2}$ \\
G & Weak & $0.172^{2}$ \\
H & Weak & $0.183^{2}$ \\
I & J & \\
J & &
\end{tabular}

${ }^{1}$ The ability of a CNS isolate to form a biofilm was classified as negative (absorbance at $490 \mathrm{~nm}, \mathrm{~A}_{490}<0.110$ ), weak $\left(\mathrm{A}_{490} 0.110-0.500\right)$, or moderate ( $\mathrm{A}_{490}$ 0.500-1.500; Tremblay et al., 2013).

${ }^{2}$ From Tremblay et al. (2013). multispecies biofilms (Burmølle et al., 2014). Isolates of CNS recovered from dairy cows have been reported to form biofilms (Piessens et al., 2012; Simojoki et al., 2012; Tremblay et al., 2013), but this finding was not associated with an increase in SCC (Simojoki et al., 2012; Tremblay et al., 2013). Still, biofilms might also facilitate the environmental transmission of CNS and support their persistence (Tremblay et al., 2013). Specifically, the production of strong biofilms by CNS isolates was associated with later stages of the lactation cycle (Tremblay et al., 2013). Furthermore, biofilm formation decreases CNS susceptibility toward commonly used antibiotics on dairy farms (Tremblay et al., 2014). In the context of biofilm formation, interactions between CNS and other mastitis pathogens has yet to be investigated. The objective of this study was to investigate the effect of CNS with a weak-biofilm phenotype on the biofilm formation of staphylococci associated with bovine mastitis.

\section{MATERIALS AND METHODS}

\section{Bacterial Strains and Growth Conditions}

Coagulase-negative staphylococci and Staph. aureus isolates were obtained from the Mastitis Pathogen Culture Collection, managed by the Canadian Bovine Mastitis and Milk Quality Research Network (St-Hyacinthe, QC, Canada; Reyher et al., 2011). Isolates of CNS were first selected from the 5 main species found on Canadian farms (i.e., Staphylococcus chromogenes, Staphylococcus simulans, Staphylococcus xylosus, Staphylococcus haemolyticus, and Staphylococcus epidermidis; Fry et al., 2014; Tables 1 and 2). The 5 Staph. aureus isolates that were previously described as strong-biofilm producers were also selected from the Mastitis Pathogen Culture Collection to represent the predominant spa types found in Canada, plus 1 methicillin-resistant Staph. aureus (Veh et al., 2015; Table 2). The isolates were assigned to a species by amplifying and sequencing the staphylococcal rpoB gene (Fry et al., 2014). This identification was then confirmed using matrix-assisted laser desorption/ionization-time of flight (MALDI-ToF) mass spectrometry analysis (Cameron et al., 2017). We obtained Staph. chromogenes isolate 2, a characterized bacteriocin producer, from Sarne De Vliegher (Ghent University, Belgium). Isolates of CNS and Staph. aureus were cultured on brain heart infusion $(\mathbf{B H I})$ agar and incubated for $16 \mathrm{~h}$ at $37^{\circ} \mathrm{C}$.

\section{Single-Species Biofilm Assay}

Biofilms from CNS and Staph. aureus were cultured in BHI supplemented with glucose (BHIG; 0.25\% wt/ 
vol) in 96-well microtiter plates (Corning Costar \#3595; Corning Inc., Corning, NY) as described previously (Tremblay et al., 2013). Briefly, colonies from BHI agar were suspended in BHIG to a 0.5 McFarland standard, and $200 \mu \mathrm{L}$ was aliquoted in 3 wells. The plate was then incubated for $24 \mathrm{~h}$ at $37^{\circ} \mathrm{C}$. After incubation, cells were removed by washing the wells 3 times with PBS. The biofilms were air-dried and stained with $0.1 \%$ (wt/vol) safranin for $10 \mathrm{~min}$. The stain was then released with $200 \mu \mathrm{L}$ of the destaining solution $[50 \%$ ( $\mathrm{vol} / \mathrm{vol}$ ) ethanol, $50 \%$ (vol/vol) glacial acetic acid] and quantified by measuring the absorbance at $490 \mathrm{~nm}\left(\mathbf{A}_{490}\right)$. Each bacterial isolate was tested in 3 wells on 3 independent days.

Table 2. Bacterial isolates (symbols correlate to those in Figure 1) with a strong-biofilm phenotype ${ }^{1}$ used in this study

\begin{tabular}{|c|c|}
\hline Bacterial species and isolates & Biofilm $\left(\mathrm{A}_{490}\right)$ \\
\hline \multicolumn{2}{|l|}{ Staphylococcus chromogenes } \\
\hline $101(\bullet)$ & $1.686^{2}$ \\
\hline $102(\boldsymbol{\square})$ & $3.500^{2}$ \\
\hline $103(\boldsymbol{\Delta})$ & $3.466^{2}$ \\
\hline $104(\bullet)$ & $3.334^{2}$ \\
\hline $105(\boldsymbol{\nabla})$ & $2.823^{2}$ \\
\hline \multicolumn{2}{|l|}{ Staphylococcus simulans } \\
\hline $106(\bullet)$ & $3.124^{2}$ \\
\hline $107(\boldsymbol{\square})$ & $3.559^{2}$ \\
\hline $108(\boldsymbol{\Delta})$ & $2.759^{3}$ \\
\hline $109(\bullet)$ & $1.906^{2}$ \\
\hline $110(\boldsymbol{\nabla})$ & $3.464^{2}$ \\
\hline \multicolumn{2}{|l|}{ Staphylococcus xylosus } \\
\hline $111(\bullet)$ & $2.349^{2}$ \\
\hline $112(\boldsymbol{\square})$ & $2.195^{2}$ \\
\hline $113(\mathbf{\Delta})$ & $3.500^{2}$ \\
\hline $114(\bullet)$ & $3.060^{2}$ \\
\hline $115(\boldsymbol{\nabla})$ & $3.537^{2}$ \\
\hline \multicolumn{2}{|l|}{ Staphylococcus epidermidis } \\
\hline $116(\bullet)$ & $2.096^{3}$ \\
\hline $117(\mathbf{\square})$ & $1.420^{3}$ \\
\hline $118(\mathbf{\Delta})$ & $2.400^{3}$ \\
\hline 119 & $1.916^{3}$ \\
\hline $120(\boldsymbol{\nabla})$ & $1.960^{3}$ \\
\hline \multicolumn{2}{|l|}{ Staphylococcus haemolyticus } \\
\hline $121(\bullet)$ & $3.278^{2}$ \\
\hline $122(\boldsymbol{\square})$ & $2.620^{2}$ \\
\hline $123(\mathbf{\Delta})$ & $2.683^{2}$ \\
\hline $124(\bullet)$ & $3.192^{2}$ \\
\hline $125(\boldsymbol{\nabla})$ & $1.180^{2}$ \\
\hline \multicolumn{2}{|l|}{ Staphylococcus aureus } \\
\hline $126(\mathrm{t} 13401)(\mathbf{0})$ & $2.000^{3}$ \\
\hline $127(\mathrm{t} 13401)(\mathbf{\square})$ & $1.000^{3}$ \\
\hline $128(\mathrm{t} 13401)$ & $1.400^{3}$ \\
\hline $129(\mathrm{t} 605)$ & $2.810^{3}$ \\
\hline $130\left(\mathrm{MRSA}^{4}(\mathbf{\nabla})\right.$ & $2.060^{3}$ \\
\hline
\end{tabular}

${ }^{1}$ The ability of a CNS isolate to form a biofilm was classified as negative (absorbance at $490 \mathrm{~nm}, \mathrm{~A}_{490}<0.110$ ), weak $\left(\mathrm{A}_{490}\right.$ 0.110-0.500), moderate $\left(\mathrm{A}_{490} 0.500-1.500\right)$, or strong $\left(\mathrm{A}_{490}>1.500\right)$; Tremblay et al. (2013).

${ }^{2}$ From Tremblay et al. (2013).

${ }^{3}$ This study.

${ }^{4}$ Methicillin-resistant Staphylococcus aureus.

\section{Dual-Species Biofilm Assay}

For the CNS-CNS and CNS-Staph. aureus dualspecies biofilms, the weak-biofilm CNS suspensions and the strong-biofilm CNS or Staph. aureus suspensions were prepared as above, and $100 \mu \mathrm{L}$ from each suspension was added to a microtiter plate for a total volume of $200 \mu \mathrm{L}$ in 3 wells. The plate was incubated for 24 $\mathrm{h}$ at $37^{\circ} \mathrm{C}$ and treated as described above. In each experiment, single-species biofilms and wells with sterile BHIG acted as controls. Each assay was repeated on 3 independent days, with 3 technical replicates on each day.

\section{Dispersion of Biofilms by CNS}

Single-species biofilms were grown as described above. After incubation for $24 \mathrm{~h}$, the liquid above the biofilm was removed and $200 \mu \mathrm{L}$ of a weak-biofilm CNS suspension in BHIG was added to 3 wells with pre-established biofilms. For control purposes, bacterial suspensions were also added to wells without biofilms, and untreated biofilms were incubated with $200 \mu \mathrm{L}$ of BHIG. After another $24 \mathrm{~h}$ of incubation, the biofilms were stained as described above. Each assay was repeated on 3 independent days, with 3 technical replicates on each day.

\section{Deferred Antagonism Assay}

The deferred antagonism assay was adapted from De Vliegher et al. (2004). Briefly, CNS weak-producer colonies from BHI agar were suspended in BHIG to a 0.5 McFarland standard and streaked with a sterile swab at the center of a BHI agar Petri dish. After $24 \mathrm{~h}$ of incubation at $37^{\circ} \mathrm{C}$, the agar was turned upside down and swabbed with a 0.5 McFarland standard of CNS strong-producer colonies to achieve full coverage. After another $24 \mathrm{~h}$ of incubation, the presence of a growth inhibition zone was investigated. We used Staph. chromogenes isolate 2, a characterized bacteriocin producer obtained from S. De Vliegher, as a control strain.

\section{Colony-Forming Units on Differential and Selective Media}

Dual-species biofilms were prepared and, after a 24 -h incubation, the biofilm and planktonic cells from 3 different wells were recovered by scraping the surface with sterile pipette tips, vigorously shaken and serially diluted. The dilutions were plated on BBL CHROMagar Staph. aureus and on BBL Mannitol Salt Agar (BD, Mississauga, ON, Canada) to differentiate CNS spe- 
cies from other CNS and from Staph. aureus. Plates were incubated at $37^{\circ} \mathrm{C}$ for a minimum of $16 \mathrm{~h}$ and a maximum of $48 \mathrm{~h}$. Each assay was repeated on 2 independent days.

\section{Confocal Laser Scanning Microscopy}

Single- and dual-species biofilms were prepared as described above and stained with SYTO 9 green fluorescent nucleic acid stain (Invitrogen, Waltham, MA) as recommended by the manufacturer (https:// tools.thermofisher.com/content/sfs/manuals/mp10316. pdf). The stained biofilms were visualized by confocal laser scanning microscopy (FV1000 IX81; Olympus, Markham, ON, Canada) and acquired images using Fluoview software (Olympus).

\section{Biofilm Formation in a Microfluidic System}

Dynamic biofilm growth was evaluated using the BioFlux 200 device (Fluxion Biosciences, South San Francisco, CA). The method used to observe growing biofilms was adapted from Moormeier et al. (2013). Briefly, colonies of CNS were suspended in $4 \mathrm{~mL}$ of fresh, warmed $\left(37^{\circ} \mathrm{C}\right)$ BHIG to an optical density at $600 \mathrm{~nm}$ of approximately 1 . The microfluidic channels were dampened with prewarmed BHIG and inoculated by injecting the bacterial suspension into the output reservoir for $20 \mathrm{~s}$ at $0.5 \mathrm{dyn} / \mathrm{cm}^{2}$. The microfluidic plate was incubated for $1 \mathrm{~h}$ at $37^{\circ} \mathrm{C}$ to allow bacterial adhesion to the surface. Fresh, prewarmed, diluted BHIG $(5 \%)$ was added into the input reservoir, and the flow of fresh medium was initiated at $0.5 \mathrm{dyn} / \mathrm{cm}^{2}$ for $23 \mathrm{~h}$. Then, biofilms were washed by injecting PBS from the input reservoir for $20 \mathrm{~min}$ at $0.5 \mathrm{dyn} / \mathrm{cm}^{2}$. Each assay was repeated on 2 independent days. Images of biofilms were obtained using a microscope (CKX41; Olympus) equipped with a $40 \times$ objective, a digital camera (Retiga EX; QImaging, Surrey, BC, Canada) and the software provided with the BioFlux 200 device.

\section{Statistical Analysis}

For the microtiter plate assay, we used a 1-way ANOVA followed by a Dunnett post-test (GraphPad Prism version 5.03 software; GraphPad Software Inc., La Jolla, CA) to compare biofilm production by a bacterial isolate with a strong-biofilm phenotype in the absence of treatment to biofilm production in the presence of CNS isolates with a weak-biofilm phenotype. Differences were considered statistically significant at $P<0.05$.

\section{RESULTS}

\section{Inhibition of Biofilm Formation by Staph. chromogenes and Staph. simulans Under Static Conditions}

Preliminary results revealed that Staph. simulans isolate I, which had a weak-biofilm phenotype, reduced the biofilm formation of Staph. chromogenes, Staph. xylosus, Staph. epidermidis, and Staph. haemolyticus with a strong-biofilm phenotype (data not shown). We made similar observations for Staph. chromogenes isolate A, which had a weak-biofilm phenotype, but not with Staph. xylosus, Staph. haemolyticus, or Staph. epidermidis isolates (data not shown).

Because we found biofilm-inhibition activity mainly in Staph. chromogenes and Staph. simulans, we conducted further evaluations of 5 isolates with a weak-biofilm phenotype for each of these 2 species. After selecting these isolates, we performed dual-species biofilm assays and observed different profiles of inhibition (Figure 1, Supplemental Table S1; https://doi.org/10.3168/ jds.2017-12629). All 5 Staph. chromogenes isolates with a weak-biofilm phenotype significantly $(P<0.05$ to $P$ $<0.001$ ) inhibited biofilm formation by the 5 isolates of Staph. chromogenes, Staph. xylosus, and Staph. haemolyticus with a strong-biofilm phenotype; the effect was smaller for the 5 Staph. simulans isolates with a weak-biofilm phenotype (Figures 1A, 1C, and 1D). We also observed a reduction in biofilm formation for some Staph. epidermidis and Staph. aureus isolates with a strong-biofilm phenotype when grown in the presence of a weak-biofilm producer (Figure 1E and $1 \mathrm{~F}$ ). Overall, Staph. chromogenes isolates with a weak-biofilm phenotype had stronger biofilm-inhibition activity against each species tested, except for some Staph. simulans isolates. These isolates appeared to be less sensitive to biofilm inhibitory activity (Figure 1B). Furthermore, Staph. simulans isolate 107, with a strong-biofilm phenotype, was not inhibited by any of the CNS isolates with a weak-biofilm phenotype (Figure 1B).

We confirmed biofilm inhibitory activity by using a confocal microscope to visualize the biofilm of an isolate with a strong-biofilm phenotype (Staph. chromogenes 104) grown in the presence of 1 of the $4 \mathrm{CNS}$ with the greatest ability to inhibit biofilm formation (Staph. chromogenes C). As expected, the single-species biofilm of the Staph. chromogenes $104\left(\mathrm{~A}_{490}=2.515\right)$ appeared as a complex structure and had a thickness of approximately $120 \mu \mathrm{m}$ (Figure 2A). The single-species biofilm of the Staph. chromogenes $\mathrm{C}\left(\mathrm{A}_{490}=0.394\right)$ was very thin, with a thickness of $10 \mu \mathrm{m}$ (Figure $2 \mathrm{~B}$ ). When both isolates were mixed and grown together, the mixed-species biofilm $\left(\mathrm{A}_{490}=0.13\right)$ was very thin, 


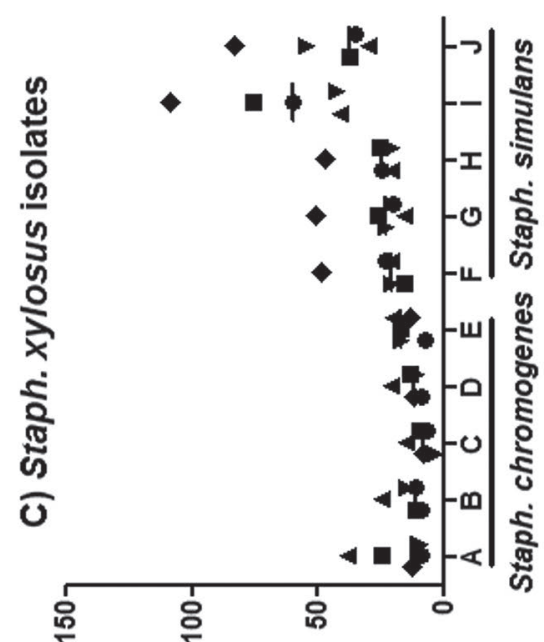

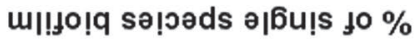

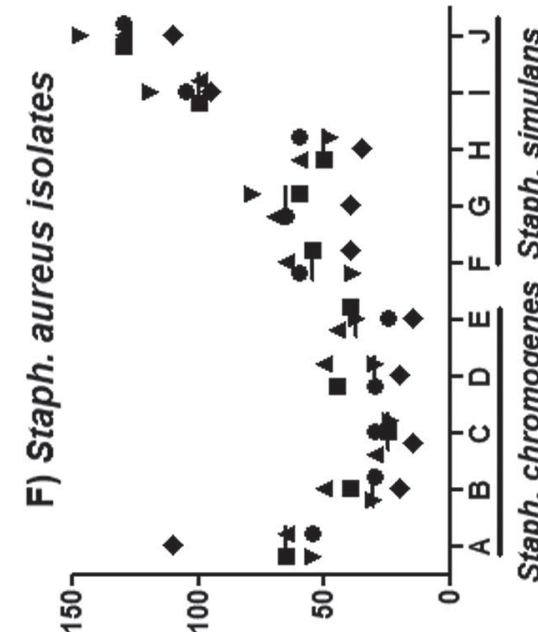

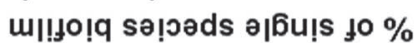

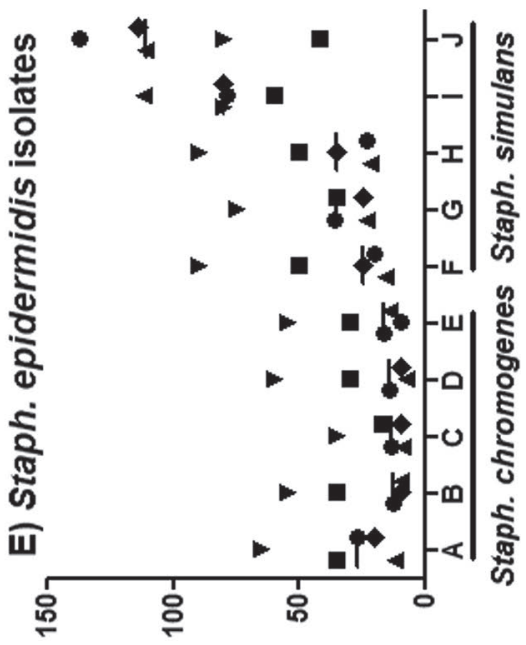

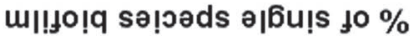

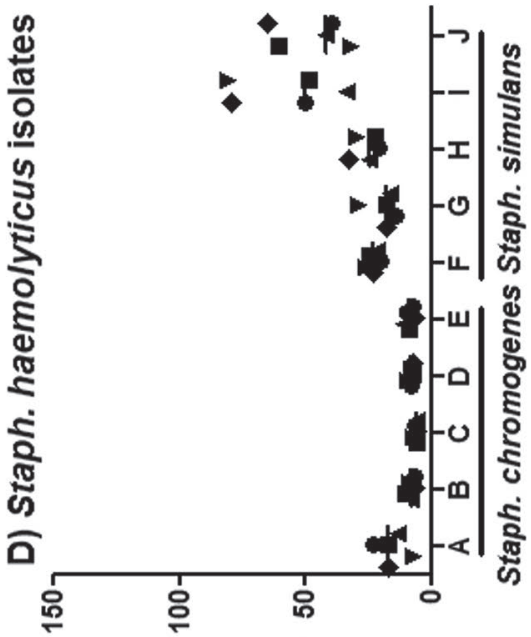

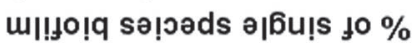

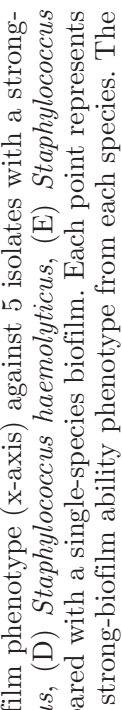

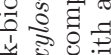

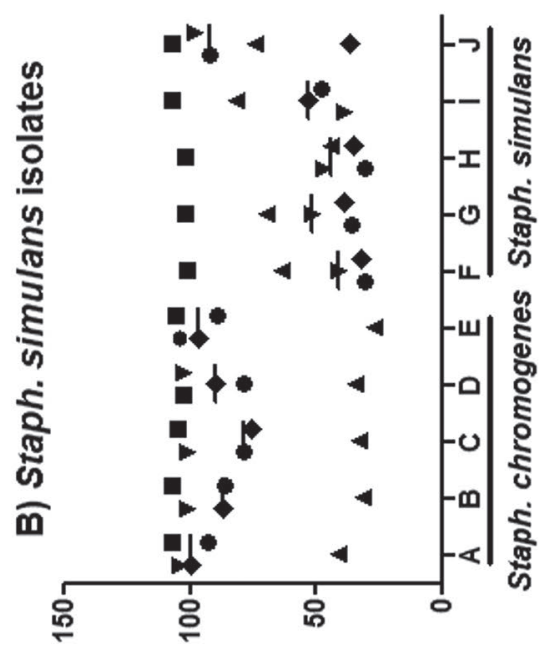

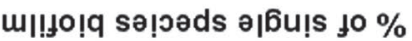

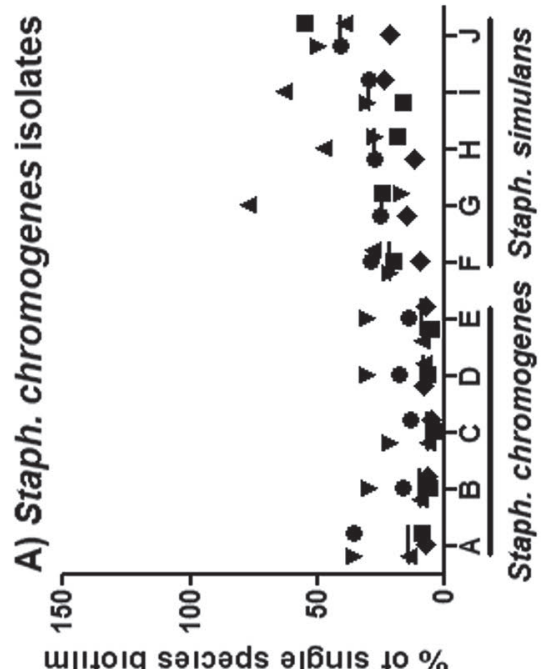

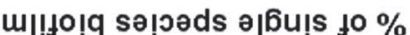

कृ

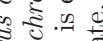

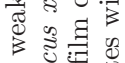

I 80.0

3 글

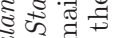

हิํำ

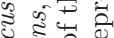

$8 \stackrel{8}{8} \stackrel{0}{\circ}$

का क्षे

网要

क क

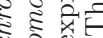

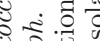

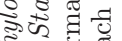

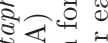

क $₫$

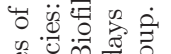

त क क क

.

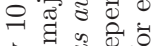

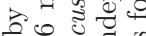

F 000.

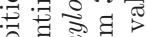

要

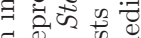

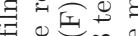

计

겨웡

0.

है हี 
with a thickness of approximately $12 \mu \mathrm{m}$ (Figure 2C). This finding confirmed that the strong-biofilm producer Staph. chromogenes 104 was unable to form its thick biofilm layer in the presence of the weak-biofilm producer Staph. chromogenes C (Figure 2C).

\section{Bacterial Growth in Dual-Species Biofilms}

Next, we performed qualitative (deferred antagonism assay) and quantitative (cfu) assays to exclude the possibility that a bactericidal effect was responsible for the observed biofilm inhibition. The CNS isolates that had a significant effect on biofilm formation (Staph. chromogenes $\mathrm{C}$ and Staph. simulans F) did not show a clear zone of inhibition against CNS with a strongbiofilm phenotype compared with the control isolate (Staph. chromogenes isolate 2 with the ability to produce a bacteriocin). Then we added Staph. chromogenes $\mathrm{C}$ and Staph. simulans F in a dual-species biofilm assay with Staph. xylosus 113, which had a strong-biofilm phenotype. In the dual-species assay, the number of Staph. xylosus decreased by $1.0 \log _{10}$ in the presence of
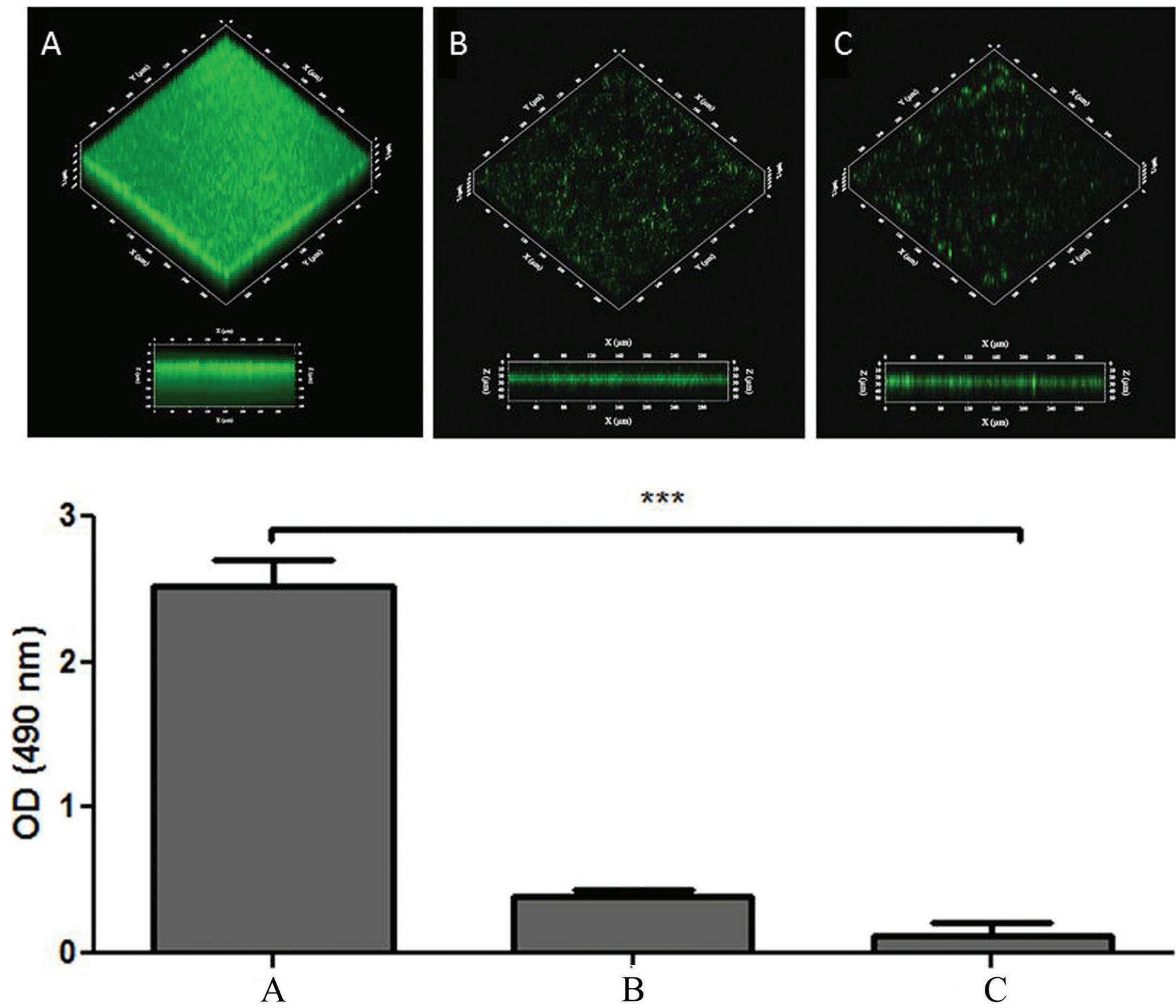

Figure 2. Biofilm formation by (A) an isolate with a strong-biofilm phenotype (Staphylococcus chromogenes 104); (B) an isolate with a weakbiofilm phenotype (Staph. chromogenes C); or (C) dual-species biofilms visualized by confocal laser scanning microscopy. The absorbance (at $490 \mathrm{~nm}, \mathrm{~A}_{490}$ ) measurements of the microtiter-plate biofilms are displayed for reference purposes. One-way ANOVA analysis was used to obtain statistical data; ${ }^{* * *} P<0.001$. OD $=$ optical density. Error bars represent the standard deviation. Color version available online. 

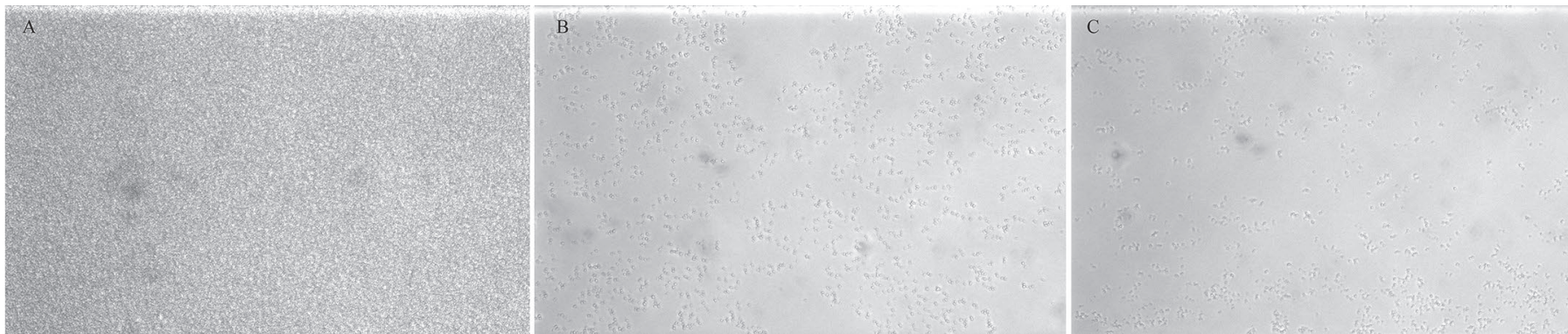

Figure 3. Microscope images of biofilms formed by (A) an isolate with a strong-biofilm phenotype (Staphylococcus chromogenes 104); (B) an isolate with a weak-biofilm phenotype (Staph. chromogenes C); or (C) dual-species biofilms. Images were obtained after $24 \mathrm{~h}$ of growth in a flow chamber of the BioFlux 200 microfluidic system (Fluxion Biosciences, South San Francisco, CA).

Staph. chromogenes $\mathrm{C}$ and by $2.02 \log _{10}$ in the presence of Staph. simulans F, compared with a monospecies biofilm. We observed similar results with Staph. haemolyticus, Staph. epidermidis, and Staph. aureus isolates that had a strong-biofilm phenotype (data not shown). As a control, we grew the Staph. chromogenes isolate 2 (DeVliegher et al., 2004) with strong-biofilm producers, and this resulted in complete growth inhibition of the strong-biofilm producers; the reduction in count (cfu) was equal to $6.32 \log _{10}$. Because the CNS with a weak-biofilm phenotype did not markedly inhibit the growth of Staphylococcus isolates with a strong-biofilm phenotype and because the reduction in count (cfu) was not important compared with the control, the observed biofilm inhibition may not have been due to antibacterial activity.

\section{Inhibition of Biofilm Formation by Staph. chromogenes and Staph. simulans Under Dynamic Conditions}

Microtiter plates used to evaluate biofilm formation under static conditions are closed systems that often lead to the accumulation of bacterial metabolic products. Furthermore, shear forces were lacking in this model, and shear forces are present at several infection sites in the host or produced by instruments used for milking. The BioFlux device is a microfluidic system with low shear force that may be used to resemble in vivo conditions (Benoit et al., 2010). Therefore, we tested the same isolate combination (Staph. chromogenes 104 and Staph. chromogenes C) in a dynamic system. The Staph. chromogenes isolate 104, which had a strong-biofilm phenotype under static conditions, also formed a homogeneous and dense biofilm in a flow system (Figure 3A). The Staph. chromogenes C isolate, which had a weak-biofilm phenotype under static conditions, formed a non-continuous biofilm characterized by scattered microcolonies in a flow system (Figure 3B). When both isolates were mixed and grown together, the resulting biofilm resembled the one observed for the single-species culture of Staph. chromogenes C (Figure 3C). The strong-biofilm producer Staph. chromogenes 104 was unable to form its typical robust biofilm in the presence of the weak-biofilm producer Staph. chromogenes $\mathrm{C}$. We observed similar results with other isolate combinations (Figure 4).

\section{Dispersion of Established Biofilms by Staph. chromogenes and Staph. simulans}

Our previous results revealed that some CNS isolates with a weak-biofilm phenotype significantly $(P<0.05$ to $P<0.001)$ reduced the biofilm formation of several staphylococcal species with a strong-biofilm phenotype (Figures 1, 2, 3, and 4). The next step was to investigate whether weak-biofilm producers could disperse pre-established biofilms. We added suspensions of the weak-biofilm producers to pre-established biofilms of strong-biofilm producers, and both species interacted for $24 \mathrm{~h}$. The effect of the weak-biofilm producer on the dispersion of biofilm formed by staphylococcal isolates with a strong-biofilm phenotype varied greatly and was species- and isolate-dependent (Figure 5, Supplemental Table S2; https://doi.org/10.3168/jds.2017-12629). Every Staph. chromogenes with a weak-biofilm phenotype and some Staph. simulans with a weak-biofilm phenotype could significantly $(P<0.05$ to $P<0.001)$ disperse the biofilm of certain Staph. simulans, Staph. xylosus, Staph. epidermidis, Staph. haemolyticus, and Staph. aureus isolates. The 5 Staph. simulans isolates with a weak-biofilm phenotype were unable to disperse the biofilms formed by Staph. chromogenes isolates with a strong-biofilm phenotype (Figure 5A). Some CNS isolates with a weak-biofilm phenotype could also disperse the biofilms formed by other staphylococcal isolates. 


\section{DISCUSSION}

The effect of pre-existing CNS colonization on new infections is a major topic of discussion (Reyher et al., 2012a; Vanderhaeghen et al., 2014), and conflicting results have been reported on this effect. The exact nature of the observed effect with CNS is still unknown. Interspecies interaction in bacteria is complex, and multiple factors influence the outcomes, including biofilm formation. Biofilm formation may be an important factor for the persistence of CNS in the intramammary environment (Tremblay et al., 2013). The objective of our study was to investigate the interactions between CNS and Staph. aureus in the context of biofilm formation, specifically, the effect of CNS with a weak-biofilm phenotype on the biofilm formation of other staphylococci.

We observed that Staph. chromogenes and Staph. simulans isolates with a weak-biofilm phenotype had the ability to inhibit biofilm formation by other Staphylococcus isolates. We observed this inhibition for isolates from each of the 5 major CNS species and for Staph. aureus. We also observed that the inhibition occurred under static and dynamic biofilm conditions. For example, the strong-biofilm producer Staph. chromogenes 104 was unable to form its thick and robust biofilm layer in the presence of the weak-biofilm producer Staph. chromogenes $\mathrm{C}$ (Figures $2 \mathrm{C}$ and $3 \mathrm{C}$ ). The results observed under dynamic conditions (Figures 3 and 4) confirmed the biofilm-inhibition properties of some CNS isolates and suggested that the inhibitory activity was not solely dependent on bacterial metabolic products accumulat- ing in a closed system. To the best of our knowledge, this was the first study to show Staph. chromogenes, Staph. haemolyticus, and Staph. xylosus biofilm formation in a BioFlux system. Importantly, we identified 4 CNS isolates (Staph. chromogenes $\mathrm{C}$ and E and Staph. simulans $\mathrm{F}$ and $\mathrm{H})$ that could significantly $(P<0.05$ to $P<0.001)$ inhibit biofilm formation by at least $50 \%$ in 76 to $83 \%$ of the staphylococcal isolates tested (Figure 1). Overall, the Staph. chromogenes isolates appeared to have stronger biofilm-inhibition activity than the Staph. simulans isolates. Furthermore, the Staph. haemolyticus and Staph. xylosus isolates seemed to be more sensitive to this biofilm-inhibition effect. The variation we found in inhibitory effects among species was in agreement with the latest literature, which indicates that the beneficial or harmful effect of CNS IMI on secondary infections appears to be species-dependent (Vanderhaeghen et al., 2014). Furthermore, we showed that the biofilm inhibitory effect appeared to depend on the isolate or combination, suggesting that more than 1 mechanism might be involved.

The degree of biofilm dispersion in assays for the effect of pre-established biofilms was not as important as that observed for biofilm inhibition. Indeed, the 4 CNS isolates that had a significant effect on biofilm formation (Staph. chromogenes $\mathrm{C}$ and E, and Staph. simulans $\mathrm{F}$ and $\mathrm{H})$ were able to significantly $(P<0.05$ to $P<$ 0.001 ) disperse at least $50 \%$ of the biofilm preformed by 23 to $43 \%$ of the staphylococcal isolates tested (Figure 5). This finding could be explained by the fact that different factors and mechanisms are involved in staphylococci biofilm formation and dispersion (Otto,
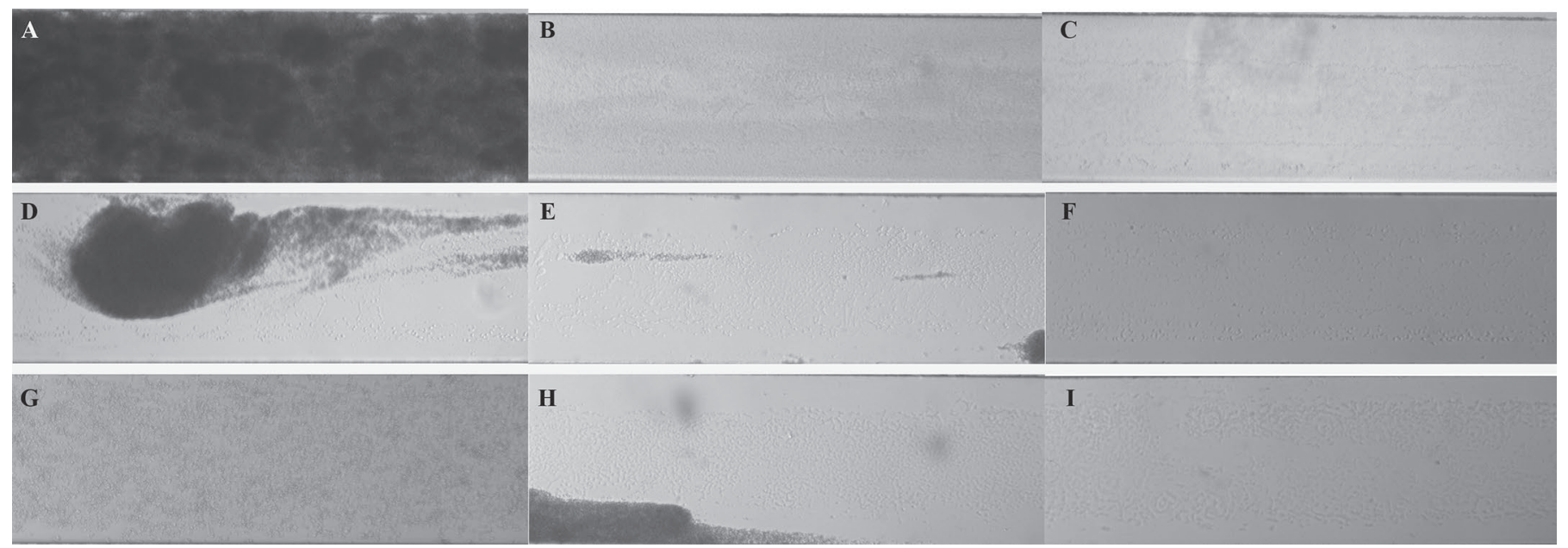

Figure 4. Microscope images of biofilms formed by isolates with a strong-biofilm phenotype: (A) Staphylococcus epidermidis 120, (D) Staphylococcus xylosus 113, and (G) Staphylococcus haemolyticus 122; or a weak-biofilm phenotype: (B) Staphylococcus chromogenes E, (E) Staphylococcus simulans F, and (H) Staph. simulans H grown as single species (A, B, D, E, G, and H) or dual-species biofilms (C, F, and I). Images were obtained after $24 \mathrm{~h}$ of growth in a flow chamber of the BioFlux 200 microfluidic system (Fluxion Biosciences, South San Francisco, $\mathrm{CA})$. 

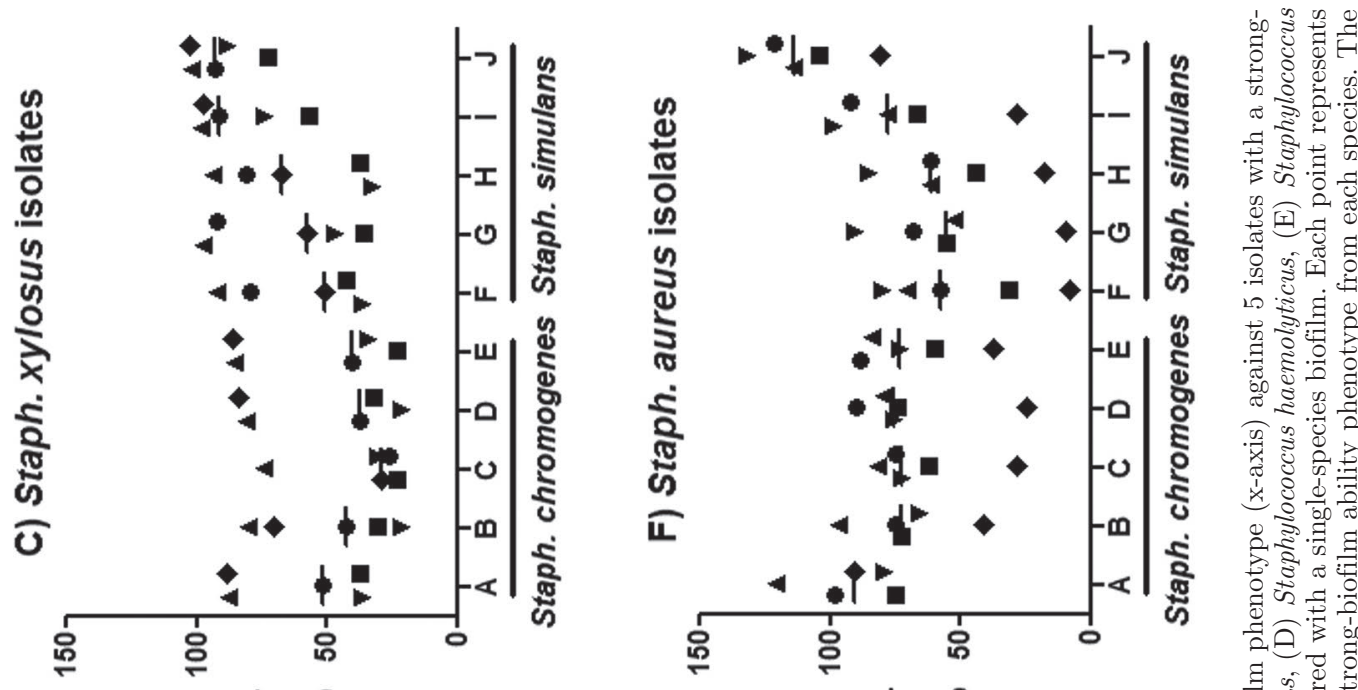

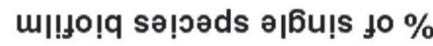

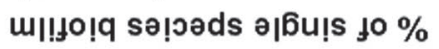

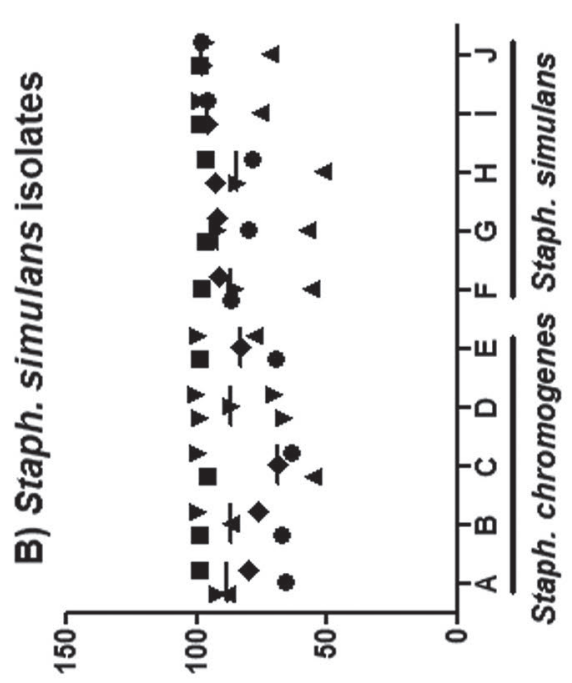

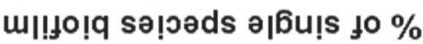

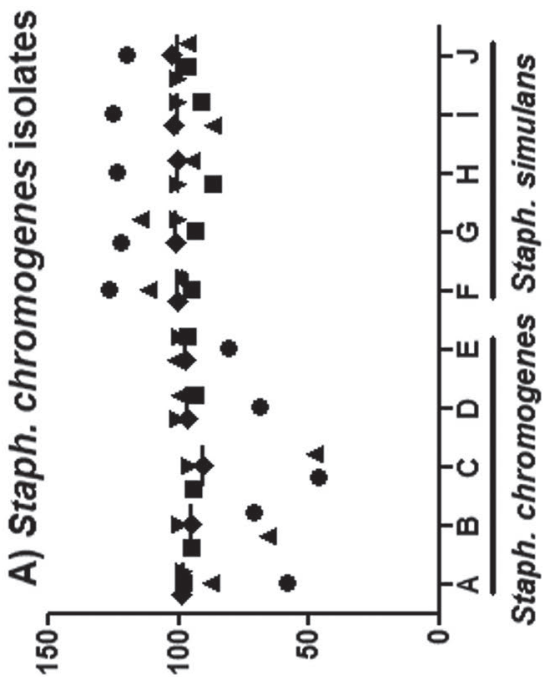

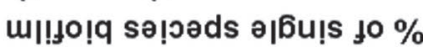

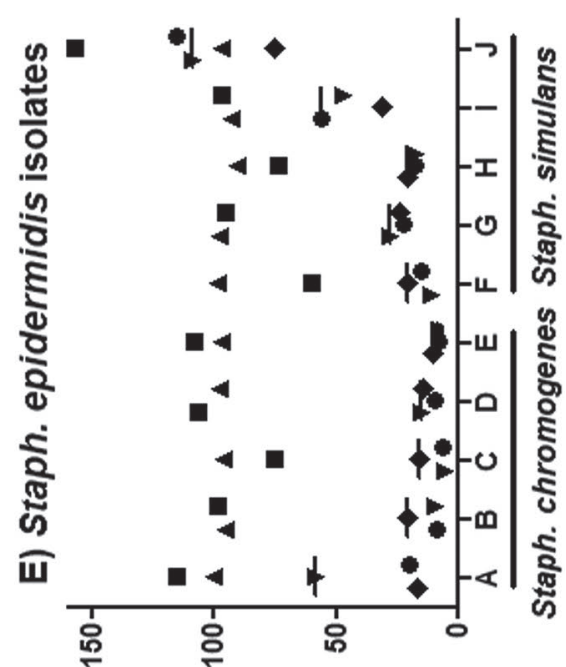

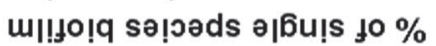

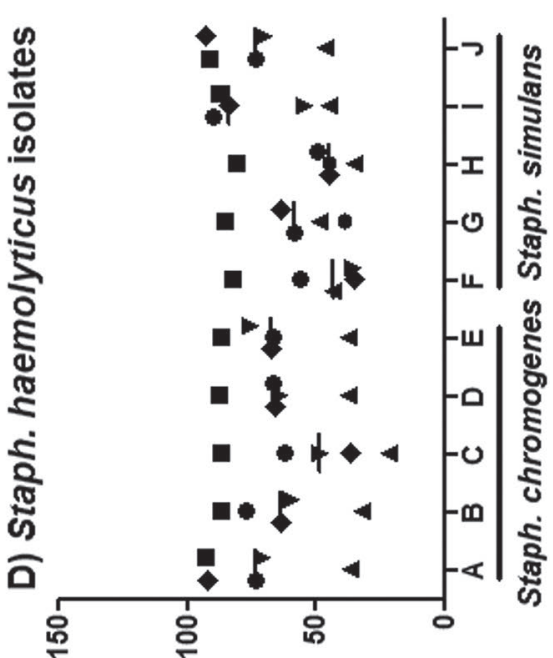

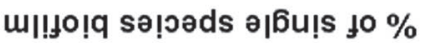

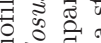

if

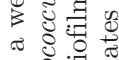

견 3

3 ․․․․․․

욜

(s)

उั

8 댕ำ

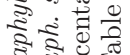

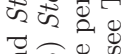

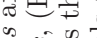

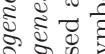

हैं है.

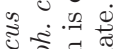

可造

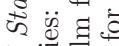

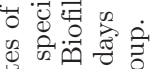

党.

의웛

궁 원

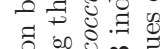

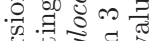

स्द छ :

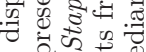

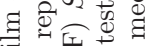

萌

is

10.0.

की है छ 
2013). Indeed, the inhibition of biofilm formation can be achieved by preventing attachment of the bacteria to the surface. For example, DNase I will cleave extracellular DNA (eDNA) in the biofilm matrix of Staph. aureus and Pseudomonas aeruginosa and prevent biofilm formation on abiotic surfaces (Mann and al, 2009). Additionally, quorum-sensing inhibition by hamamelitannin will prevent intracellular signals by repressing RNA III, a quorum-sensing regulator in Staph. aureus and Staph. epidermidis (Kiran and al., 2008). Biofilm dispersion can be achieved by using matrix-degrading enzymes such as dispersin B, which depolymerize poly$\mathrm{N}$-acetyl-glucosamine, a polysaccharide found in some staphylococcal biofilms (Kaplan and al., 2004).

Some CNS isolated from dairy cows are known to produce bacteriocins that have antibacterial activity against other mastitis pathogens, including other CNS species and Staph. aureus (dos Santos Nascimento et al., 2005; Ceotto et al., 2010; Brito et al., 2011; Braem et al., 2014). We observed no growth inhibition using the deferred antagonism test on BHI agar plates. Furthermore, when we determined cfu in our mixed-biofilm assays, we observed no marked growth inhibition when isolates were grown with the 4 CNS isolates that had the strongest biofilm-inhibition activity. These CNS isolates did not seem to produce bacteriocins under the conditions tested, and the inhibition of biofilm formation did not seem to be due to bactericidal activity.

Some CNS isolates with a weak-biofilm phenotype can negatively affect the biofilm-forming ability of other staphylococci, including Staph. aureus, one of the most prevalent pathogens causing IMI in dairy cattle (Barnouin et al., 2005; Piepers et al., 2007; Sato et al., 2008; Petrovski et al., 2009; Olde Riekerink et al., 2010). These findings were in contrast with most studies, which have focused on the cooperative interactions and advantages provided by living in a biofilm community (e.g., antibiotic resistance and protection against immune defenses; Harriott and Noverr, 2009; Peters and al., 2010; Elias and Banin, 2012; Burmølle et al., 2014). Recent studies have, however, highlighted the importance of competitive interactions in biofilm communities (Rendueles and Ghigo, 2012). For example, Streptococcus pneumoniae can eradicate a preformed Staph. aureus biofilm using physical contact (Khan et al., 2016). Another study observed that spatial competition between Lactococcus lactis and Listeria monocytogenes in mixed-species biofilms resulted in the inhibition of L. monocytogenes (Habimana et al., 2011).

The mechanisms behind the biofilm-inhibition and dispersion effect of CNS have yet to be characterized, and their effect on other important mastitis pathogens, including Streptococcus spp., Klebsiella spp., and Esch- erichia coli should also be evaluated to determine the spectrum of this activity.

\section{ACKNOWLEDGMENTS}

This research was supported by a grant from the Dairy Research Cluster II (Dairy Farmers of Canada, Agriculture and Agri-Food Canada, Canadian Dairy Network, Canadian Dairy Commission) through the Canadian Bovine Mastitis and Milk Quality Research Network. CG and AMG are the recipients of a NSERCCREATE scholarship in milk quality. CG is also the recipient of a FRQNT Op+Lait Strategic Cluster scholarship. We thank Sarne De Vliegher (Ghent University, Belgium) for the generous gift of the Staph. chromogenes 2 isolate. We also thank Frederic Berthiaume for his help with the confocal laser scanning microscopy, and Marguerite Cameron and Greg Keefe (University of Prince Edward Island, Canada) for their help with CNS species confirmation by MALDI-ToF.

\section{REFERENCES}

Barnouin, J., S. Bord, S. Bazin, and M. Chassagne. 2005. Dairy management practices associated with incidence rate of clinical mastitis in low somatic cell score herds in France. J. Dairy Sci. 88:3700-3709.

Benoit, M. R., C. G. Conant, C. Ionescu-Zanetti, M. Schwartz, and A. Matin. 2010. New device for high-throughput viability screening of flow biofilms. Appl. Environ. Microbiol. 76:4136-4142.

Braem, G., B. Stijlemans, W. Van Haken, S. De Vliegher, L. De Vuyst, and F. Leroy. 2014. Antibacterial activities of coagulase-negative staphylococci from bovine teat apex skin and their inhibitory effect on mastitis-related pathogens. J. Appl. Microbiol. 116:1084-1093.

Brito, M. A., G. A. Somkuti, and J. A. Renye Jr... 2011. Production of antilisterial bacteriocins by staphylococci isolated from bovine milk. J. Dairy Sci. 94:1194-1200.

Burmølle, M., D. Ren, T. Bjarnsholt, and S. J. Sørensen. 2014. Interactions in multispecies biofilms: Do they actually matter? Trends Microbiol. 22:84-91.

Cameron, M., H. W. Barkema, J. De Buck, S. De Vliegher, M. Chaffer, J. Lewis, and G.P. Keefe. 2017. Identification of bovine-associated coagulase-negative staphylococci by matrix-assisted laser desorption/ionization time-of-flight mass spectrometry using a direct transfer protocol. J Dairy Sci. 100:2137-2147.

Ceotto, H., H. Holo, K. F. da Costa, S. Jdos Nascimento, Z. Salehian, I. F. Nes, and C. Mdo Bastos. 2010. Nukacin 3299, a lantibiotic produced by Staphylococcus simulans 3299 identical to nukacin ISK-1. Vet. Microbiol. 146:124-131.

Costerton, J. W., P. S. Stewart, and E. P. Greenberg. 1999. Bacterial biofilms: A common cause of persistent infections. Science 284:1318-1322.

De Vliegher, S., G. Opsomer, A. Vanrolleghem, L. A. Devriese, O. C. Sampimon, H. W. Barkema, F. Haesebrouck, and A. de Kruif. 2004. In vitro growth inhibition of major mastitis pathogens by Staphylococcus chromogenes originating from teat apices of dairy heifers. Vet. Microbiol. 101:215-221.

De Vuyst, L., and F. Leroy. 2007. Bacteriocins from lactic acid bacteria: Production, purification, and food applications. J. Mol. Microbiol. Biotechnol. 13:194-199.

dos Santos Nascimento, J., P. C. Fagundes, M. A. de Paiva Brito, K. R. dos Santos, and M. do Carmo de Freire Bastos. 2005. Production of bacteriocins by coagulase-negative staphylococci involved in bovine mastitis. Vet. Microbiol. 106:61-71. 
Elias, S., and E. Banin. 2012. Multi-species biofilms: Living with friendly neighbors. FEMS Microbiol. Rev. 36:990-1004.

Fry, P. R., J. R. Middleton, S. Dufour, J. Perry, D. Scholl, and I. Dohoo. 2014. Association of coagulase-negative staphylococcal species, mammary quarter milk somatic cell count, and persistence of intramammary infection in dairy cattle. J. Dairy Sci. 97:4876-4885.

Habimana, O., L. Guillier, S. Kulakauskas, and R. Briandet. 2011. Spatial competition with Lactococcus lactis in mixed-species continuous-flow biofilms inhibits Listeria monocytogenes growth. Biofouling 27:1065-1072.

Harriott, M. M., and M. C. Noverr. 2009. Candida albicans and Staphylococcus aureus form polymicrobial biofilms: Effects on antimicrobial resistance. Antimicrob. Agents Chemother. 53:3914-3922.

Hathroubi, S., M. A. Mekni, P. Domenico, D. Nguyen, and M. Jacques. 2017. Biofilms: Microbial shelters against antibiotics. Microb. Drug Resist. 23:147-156.

Jacques, M., V. Aragon, and Y. D. N. Tremblay. 2010. Biofilm formation in bacterial pathogens of veterinary importance. Anim. Health Res. Rev. 11:97-121.

Kaplan, J. B., K. Velliyagounder, C. Ragunath, H. Rohde, D. Mack, J. K. Knobloch, and N. Ramasubbu. 2004. Genes involved in the synthesis and degradation of matrix polysaccharide in Actinobacillus actinomycetemcomitans and Actinobacillus pleuropneumoniae biofilms. J. Bacteriol. 186:8213-8220.

Khan, F., X. Wu, G. L. Matzkin, M. A. Khan, F. Sakai, and J. E. Vidal. 2016. Streptococcus pneumoniae eradicates preformed Staphylococcus aureus biofilms through a mechanism requiring physical contact. Front. Cell. Infect. Microbiol. 6:104.

Kiran, M. D., N. V. Adikesavan, O. Cirioni, A. Giacometti, C. Silvestri, G. S. Calise, R. Ghiselli, V. Saba, F. Orlando, M. Shoham, and N. Balaban. 2008. Discovery of a quorum-sensing inhibitor of drug-resistant staphylococcal infections by structure-based virtual screening. Mol. Pharmacol. 73:1578-1586.

Kuboniwa, M., G. D. Tribble, C. E. James, A. O. Kilic, L. Tao, M. C. Herzberg, S. Shizukuishi, and R. J. Lamont. 2006. Streptococcus gordonii utilizes several distinct gene functions to recruit Porphyromonas gingivalis into a mixed community. Mol. Microbiol. 60:121-139.

Mann, E. E., K. C. Rice, B. R. Boles, J. L. Endres, D. Ranjit, L. Chandramohan, L. H. Tsang, M. S. Smeltzer, A. R. Horswill, and K. W. Bayles. 2009. Modulation of eDNA release and degradation affects Staphylococcus aureus biofilm maturation. PLoS One 4:e5822.

Matthews, K. R., R. J. Harmon, and B. E. Langlois. 1991. Effect of naturally occurring coagulase-negative staphylococci infections on new infections by mastitis pathogens in the bovine. J. Dairy Sci. $74: 1855-1859$

Miquel, S., R. Lagrafeuille, B. Souweine, and C. Forestier. 2016. Antibiofilm activity as a health issue. Front. Microbiol. 7:592.

Moormeier, D. E., J. L. Endres, E. E. Mann, M. R. Sadykov, A. R. Horswill, K. C. Rice, P. D. Fey, and K. W. Bayles. 2013. Use of microfluidic technology to analyze gene expression during Staphylococcus aureus biofilm formation reveals distinct physiological niches. Appl. Environ. Microbiol. 79:3413-3424.

Olde Riekerink, R. G., H. W. Barkema, D. T. Scholl, D. E. Poole, and D. F. Kelton. 2010. Management practices associated with the bulk-milk prevalence of Staphylococcus aureus in Canadian dairy farms. Prev. Vet. Med. 97:20-28.

Otto, M. 2013. Staphylococcal infections: Mechanisms of biofilm maturation and detachment as critical determinants of pathogenicity. Annu. Rev. Med. 64:175-188.

Peters, B. M., M. A. Jabra-Rizk, M. A. Scheper, J. G. Leid, J. W. Costerton, and M. E. Shirtliff. 2010. Microbial interactions and differential protein expression in Staphylococcus aureus-Candida albicans dual-species biofilms. FEMS Immunol. Med. Microbiol. 59:493-503.

Petrovski, K. R., C. Heuer, T. J. Parkinson, and N. B. Williamson. 2009. The incidence and aetiology of clinical bovine mastitis on 14 farms in Northland, New Zealand. N. Z. Vet. J. 57:109-115.

Piepers, S., L. De Meulemeester, A. de Kruif, G. Opsomer, H. W. Barkema, and S. De Vliegher. 2007. Prevalence and distribution of mastitis pathogens in subclinically infected dairy cows in Flanders, Belgium. J. Dairy Res. 74:478-483.

Piessens, V., S. de Vliegher, B. Verbist, G. Braem, A. van Nuffel, L. de Vuyst, M. Heyndrickx, and E. van Coillie. 2012. Characterization of coagulase-negative Staphylococcus species from cows' milk and environment based on bap, icaA, and mecA genes and phenotypic susceptibility to antimicrobials and teat dips. J. Dairy Sci. 95:7027-7038.

Pyörälä, S., and S. Taponen. 2009. Coagulase-negative staphylococciEmerging mastitis pathogens. Vet. Microbiol. 134:3-8.

Rainard, P., and B. Poutrel. 1988. Effect of naturally occurring intramammary infections by minor pathogens on new infections by major pathogens in cattle. Am. J. Vet. Res. 49:327-329.

Rendueles, O., and J. M. Ghigo. 2012. Multi-species biofilms: How to avoid unfriendly neighbors. FEMS Microbiol. Rev. 36:972-989.

Reyher, K. K., I. R. Dohoo, and C. A. Muckle. 2013. Evaluation of clustering of new intramammary infections in the bovine udder, including the impact of previous infections, herd prevalence, and somatic cell count on their development. J. Dairy Sci. 96:219-233.

Reyher, K. K., I. R. Dohoo, D. T. Scholl, and G. P. Keefe. 2012b. Evaluation of minor pathogen intramammary infection, susceptibility parameters, and somatic cell counts on the development of new intramammary infections with major mastitis pathogens. J. Dairy Sci. 95:3766-3780.

Reyher, K. K., S. Dufour, H. W. Barkema, L. Des Coteaux, T. J. Devries, I. R. Dohoo, G. P. Keefe, J. P. Roy, and D. T. Scholl. 2011. The National Cohort of Dairy Farms - A data collection platform for mastitis research in Canada. J. Dairy Sci. 94:1616-1626.

Reyher, K. K., D. Haine, I. R. Dohoo, and C. W. Revie. 2012a. Examining the effect of intramammary infections with minor mastitis pathogens on the acquisition of new intramammary infections with major mastitis pathogens - A systematic review and meta-analysis. J. Dairy Sci. 95:6483-6502.

Rickard, A. H., P. Gilbert, N. J. High, P. E. Kolenbrander, and P. S. Handley. 2003. Bacterial coaggregation: An integral process in the development of multi-species biofilms. Trends Microbiol 11:94-100.

Sampimon, O., H. W. Barkema, I. Berends, J. Sol, and T. Lam. 2009 Prevalence of intramammary infection in Dutch dairy herds. J. Dairy Res. 76:129-136.

Sato, K., P. C. Bartlett, L. Alban, J. F. Agger, and H. Houe. 2008. Managerial and environmental determinants of clinical mastitis in Danish dairy herds. Acta Vet. Scand. 50:4.

Simojoki, H., P. Hyvönen, C. Plumed Ferrer, S. Taponen, and S. Pyörälä. 2012. Is the biofilm formation and slime producing ability of coagulase-negative staphylococci associated with the persistence and severity of intramammary infection? Vet. Microbiol. 158:344-352.

Tenhagen, B. A., G. Koster, J. Wallmann, and W. Heuwieser. 2006. Prevalence of mastitis pathogens and their resistance against antimicrobial agents in dairy cows in Brandenburg, Germany. J. Dairy Sci. 89:2542-2551.

Tremblay, Y. D. N., V. Caron, A. Blondeau, S. Messier, and M. Jacques. 2014. Biofilm formation by coagulase-negative staphylococci: Impact on the efficacy of antimicrobials and disinfectants commonly used on dairy farms. Vet. Microbiol. 172:511-518.

Tremblay, Y. D. N., D. Lamarche, P. Chever, D. Haine, S. Messier, and M. Jacques. 2013. Characterization of the ability of coagulasenegative staphylococci isolated from the milk of Canadian farms to form biofilms. J. Dairy Sci. 96:234-246.

Vanderhaeghen, W., S. Piepers, F. Leroy, E. Van Coillie, F. Haesebrouck, and S. De Vliegher. 2014. Invited review: Effect, persistence, and virulence of coagulase-negative Staphylococcus species associated with ruminant udder health. J. Dairy Sci. 97:5275-5293.

Veh, K. A., R. C. Klein, C. Ster, G. Keefe, P. Lacasse, D. Scholl J. P. Roy, D. Haine, S. Dufour, B. G. Talbot, A. O. Ribon, and F. Malouin. 2015. Genotypic and phenotypic characterization of Staphylococcus aureus causing persistent and nonpersistent subclinical bovine intramammary infections during lactation or the dry period. J. Dairy Sci. 98:155-168. 